\title{
SME 2.0: Roadmap towards Web 2.0-Based Open Innovation in SME-Networks - A Case Study Based Research Framework
}

\author{
Nadine Lindermann, Sylvia Valcárcel, Mario Schaarschmidt, \\ and Harald von Kortzfleisch \\ University of Koblenz-Landau, Institute for Management, \\ Computer Science Faculty, Universitaetsstrasse 1, Germany
}

\begin{abstract}
Small- and medium sized enterprises (SMEs) are of high social and economic importance since they represent $99 \%$ of European enterprises. With regard to their restricted resources, SMEs are facing a limited capacity for innovation to compete with new challenges in a complex and dynamic competitive environment. Given this context, SMEs need to increasingly cooperate to generate innovations on an extended resource base. Our research project $^{1}$ focuses on the aspect of open innovation in SME-networks enabled by Web 2.0 applications and referring to innovative solutions of non-competitive daily life problems. Examples are industrial safety, work-life balance issues or pollution control. The project raises the question whether the use of Web 2.0 applications can foster the exchange of creativity and innovative ideas within a network of SMEs and hence catalyze new forms of innovation processes among its participants. Using Web 2.0 applications within SMEs implies consequently breaking down innovation processes to employees' level and thus systematically opening up a heterogeneous and broader knowledge base to idea generation. In this paper we address first steps on a roadmap towards Web 2.0-based open innovation processes within SME-networks. It presents a general framework for interaction activities leading to open innovation and recommends a regional marketplace as a viable, trust-building driver for further collaborative activities. These findings are based on field research within a specific SME-network in Rhineland-Palatinate Germany, the "WirtschaftsForum Neuwied e.V.", which consists of roughly 100 heterogeneous SMEs employing about 8,000 workers.
\end{abstract}

\section{Introduction}

Small- and medium sized enterprises (SMEs) are increasingly confronted with complex and dynamic problems of daily work life. Examples are worker's health protection, industrial safety, work-life balance issues, conservation of energy or pollution control. Since these non-competitive aspects are across all activities of a company's value chain, they also become important to primary activities and thus

\footnotetext{
${ }^{1}$ The research project is funded by the German Federal Ministry of Education and Research (BMBF).
} 
require innovative solutions. SMEs need to cooperate in order to generate innovative solutions on an extended resource base.

Within our research project we explore new management strategies for collaboration in SME-networks related to innovative, cooperative solutions for daily work life problems. We systematically analyze concepts and models of self-organization and information technology (IT) in the context of Web 2.0 and assume that

- Many employees are confident in using Web 2.0-applications in their private lives and thus are motivated to participate on a Web 2.0-platform in a cross-organizational environment,

- Heterogeneous groups offer a high potential for creativity and innovation.

According to these assumptions we focus on the capability of Web 2.0 applications to integrate employees from different companies and to profit from their collaborative creativity. Thus the project raises the question- whether the use of Web 2.0 applications can foster the exchange of creativity and innovative ideas within a network of SMEs and hence catalyze new forms of innovation processes among its participants. We follow an incremental "action research design" (Romme 2003) collecting organizational and technical requirements for Web 2.0-based collaborative structures as well as developing and implementing a Web 2.0-application that supports inter-organizational creative processes within SME-networks. The project is based on field research within a specific SME-network in Rhineland-Palatinate Germany, the "WirtschaftsForum Neuwied e.V.".

This paper presents first results of our research project. It aims at depicting first steps on a roadmap towards Web 2.0-based open innovation processes within SMEnetworks. First of all we introduce the network "WirtschaftsForum Neuwied e.V." we are analyzing and give an overview of the characteristics and challenges it is facing with regard to Web 2.0 applications. We then focus on general aspects of Web 2.0based open innovation. Afterwards we present first results of an interview series conducted with managers of the network's companies. Finally we introduce a general framework for interaction activities leading to open innovation and recommend a regional marketplace as a viable, trust-building driver for further collaborative activities.

\section{SME 2.0: Challenges of a Cooperative Research Project}

In the European economy, SMEs play a major role since they represent $99 \%$ of all Europe enterprises and thus are a main source of entrepreneurial skills, employment and innovation (European Commission 2003). In recent years, joining cross-organizational networks has become increasingly important for SMEs wishing to access an extended resource base and operate on the basis of it (Human and Provan 1996; Street and Cameron 2007). In general, a network is an association of at least three autonomous enterprises for the purpose of a corporate task fulfillment. By combining and coordinating resources and organizational functions, they aim at achieving competitive advantages to create win-win-situations for all participating partners (Corsten 2001; Picot et al. 2003). Thereby cooperation generates synergies for innovative business solutions where the combination of resources exceeds the sum of individual efforts 
(European Commission 2003a). The "WirtschaftsForum Neuwied e.V." represents a SME-network in consideration which is described according to its characteristics and challenges below.

\section{1 "WirtschaftsForum Neuwied e.V."}

The "WirtschaftsForum Neuwied e.V." is a regional network in the north of Rhineland-Palatinate in Germany that consists of roughly 100 SMEs employing about 8,000 workers. It was founded in 2002 and comprises companies primarily from the industry and business sector in the surrounding area of Neuwied. The SME-network is heterogeneous in structure regarding respective size of the cooperating companies, represented branches, products and services and technological affinity. It focuses on non-competitive activities and aims at fostering knowledge transfer between its members and enhancing collaboration and business relations. In this regard it is facing challenges and problems generally related to SMEs (Bellmann and Gerster 2006; Street and Cameron 2007; Thielemann 1996):

- The management of SMEs is highly influenced by the personality of the owners and their attitude towards doing business. Joining a network is usually decided on the executives' level only, while employees are barely integrated into the collaborative work. This translates into scant use of expert knowledge on the operational level within the SME-network.

- IT is not yet widely implemented. Within the "WirtschaftsForum Neuwied e.V." many cooperating partners are hardly using IT, while others maintain a sophisticated internet-based IT infrastructure.

- The capability for innovation in SMEs is limited by restricted resources. Normally the business model is grouped around a core activity implying innovation efforts to be strictly targeted at the same field of activities.

The specific characteristics of SME-networks depicted above influence their use of Web 2.0-applications. In the following we outline the philosophy underlying Web 2.0.

\subsection{SMEs and the Use of Web 2.0}

Web 2.0 is a phenomenon that represents a changing trend in the World Wide Web (WWW). The term was coined by Tim O'Reilly in 2004 and is used for active user participation on the Internet (O'Reilly 2005). The idea of the concept is that internet content is not just to be read, listened to or observed, but also to be generated, commented on and shared with other users (O'Reilly 2005; Von Kortzfleisch et al. 2008). As it is heavily dependent on active participation on its users' side, Web 2.0 has an inherent potential for common problem solving and raising shared creativity. In this context "Enterprise 2.0" refers to the consequent application of Web 2.0 within an organizational context (McAfee 2006). Our research project broadens this perspective insofar as it addresses inter-organizational usage of Web 2.0 within a network of SMEs and introduces the term "SME 2.0".

In daily business practice, Web 2.0 use (e.g. wikis and blogs) has been observed as primarily being restricted to communication with the customer and internal information and knowledge management (CoreMedia and Berlecon Research 2007; 
McKinsey and Company 2008; The Economist Intelligence Unit 2007). Within the context of SMEs, the potential of Web 2.0 is not yet fully perceived (De Saulles 2008a; De Saulles 2008b; Social Computing News Desk 2008). Given the creative potential of Web 2.0, we analyze whether and to what extent social software is used within a network of SMEs and thus can unfetter collective intelligence. Given the philosophy of SME 2.0 and the characteristics of SME-networks, the challenges shown in figure 1 have to be dealt with:
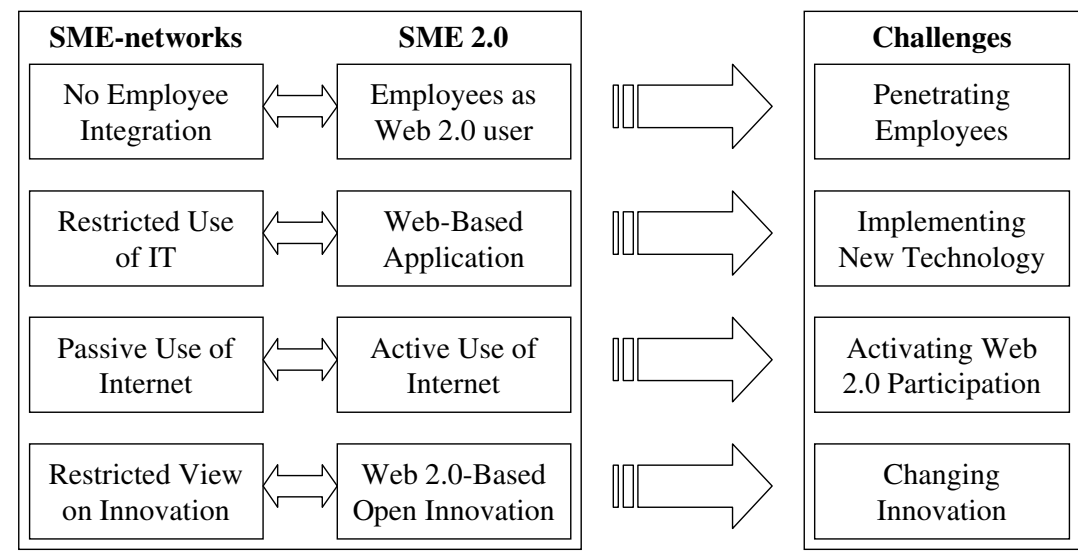

Fig. 1. Challenges of SME-networks using Web 2.0

- Within the network SMEs are primarily represented by their executives. Delegation to subordinates tends to be limited (Burns 2001), also implying they are not (sufficiently) integrated into the network's activities. According to our understanding of SME 2.0, employees should become Web 2.0-users who participate in collaborative work by transferring their knowledge across the internet platform. This requires penetrating the employees' level of the network.

- Currently, IT is hardly used within the SME-network, its use being confined to daily business matters and thus markedly short-termed (Levy and Powell 2005). Companies consequently need to be conducted to the new Web 2.0 approach.

- Internet content is passively consumed but not actively designed. User participation has to be activated (De Saulles 2008a; De Saulles 2008b).

- Our research project focuses on innovations regarding daily work life problems. Since innovations in SMEs are normally related to their primary activities, the companies have to be directed to this new aspect for innovation.

In our research project we focus on the question whether the use of Web 2.0applications can foster the exchange of creativity and innovative ideas within a SMEnetwork. A Web 2.0-application is planned to be developed to enable web-based collaborative idea generation. This approach is based on a roadmap defining the steps to be taken towards Web 2.0-based open innovation. According to the challenges we identified in figure 1, we first have to ensure acceptance and usage of the Web 2.0based platform. Therefore we analyzed general requirements on Web 2.0-applications. 
At the same time we considered aspects of Web 2.0-based open innovation that also have to be integrated into the model. These aspects are discussed in the section below.

\section{Web 2.0-Based Collaborative Open Innovation}

Open Innovation is a widely used term currently discussed in many contexts. At its core, it is the increasing usage of external sources for creating and developing new ideas which lead to innovation. In contrast to a closed innovation paradigm, firms try to include customers, users, universities and even competitors in different stages of their new product development processes (Chesbrough 2003).

The change from a closed to a more open development paradigm includes a change of the underlying mental model as well. In a closed innovation environment, firms tried to hire the smartest people to work for them, relied heavily on internal research and development activities (R\&D), and tried to control and protect their Intellectual Property (IP). In contrast, in an open innovation environment, firms are trying to work with smart people from inside and outside the company, are recognising internal R\&D activities as only a part of an innovation process, and are buying IP from outside, whenever it is needed and suitable for the current business model (Chesbrough 2003; Van der Meer 2007).

In recent years, many firms opened several parts of their innovation processes for external participation. According to the different types of possible external sources (users, customers, universities, research centres, competitors, etc) it is important to distinguish them with regard to the degree of their involvement. Most activities of integrating users or customers in innovation processes can be observed in early and late phases of the innovation process - like making use of lead users or mass customizing products (Von Hippel 2005; Piller and Walcher 2006) - whereas integrating external partners in core development activities is open to a lesser extend. In the latter case, firms mainly make use of industrial R\&D consortiums and joint ventures which generally include contractual agreements - without integrating users or customers. Furthermore, research in the area of open innovation is concentrated mostly on single users rather than on groups or communities. However, the role of communities in creating, shaping and disseminating technological and social innovations outside the boundaries of the firm is a specially promising research area (West and Lakhani 2008). Since heterogeneity is known to be a driver for creativity and communities are heterogeneous in nature, they are offering a hidden creative potential (Oldman and Cummings 1996; Alves et al. 2007; Schaarschmidt and Von Kortzfleisch 2008). Furthermore, innovation networks, whether as networks of companies or persons have the potential to act as a proxy for innovation (Martins and Terblanche 2003; Kratzer et al. 2004; Birkinshaw et al. 2007).

To sum up, open innovation is a promising trend both in theory and practice. Communities are offering a high potential for generating innovative ideas and even products as is the case for development of open source software (Osterloh and Rota 2007) or idea generating platforms (Lakhani 2008). In addition to the use of Web 2.0 as basic-democratic and more or less non-hierarchical structures, this potential is even higher (Schaarschmidt and Von Kortzfleisch 2008). Willingness to take risk for example, as an important factor in generating innovative ideas, increases, when 
hierarchical structures are missing (Dewett 2007). The challenge firms are facing therefore is to canalize community activities to transform group creativity into useful ideas.

\section{Open Innovation - Just a Theory in the Context of SME 2.0?}

The first phase of the research project aims at analyzing the organizational and technical requirements to be met for the set-up of Web 2.0-applications within the "WirtschaftsForum Neuwied e.V.". This section outlines the results of explorative interviews with executives of the project's six value partners, both from a methodological as well as content-related perspective.

\subsection{Setting Up of the Explorative Interview Phase}

The chosen research design comprises two stages: the first stage is directed at generating recommendations for the enhancement of cooperation activities within a network of SMEs. Such an enhancement of cooperation activities is argued to be an indispensable prerequisite for open innovation activities within a network. Recommendations are generated on the basis of explorative, qualitative interviews, which provide for substantial insight into the given context and lay the ground for further generation of hypotheses (Miles and Huberman 1994). In a second stage of the research, a broad-based survey will be conducted, testing the hypotheses generated beforehand.

Concretely eight managing directors out of six partner firms ("value partners") were interviewed on the basis of a semi-standardized questionnaire. The value partners represent SMEs of different branches within the network and act as lead users who test the applications and diffuse them among the cooperating partners. The interviews were directed at determining the goals and needs of small and mediumsized companies cooperating within the network on a strategic level. They provide for general information about the company in question and its cooperation activities within "WirtschaftsForum Neuwied e.V.", as well as for requirements, benefits and objections concerning the use of Web 2.0. The following synthesis is elaborated along the thematic blocks of the questionnaire.

\subsection{Requirements for SME 2.0: First Results of an Explorative Study}

1. Actual challenges of SMEs: The main challenges of SMEs are customer loyalty and customer acquisition as well as market observation. Some SMEs are operating on nearly saturated markets and have to continuously generate new ideas and open up additional business segments. Since these companies might be founded on a single business idea, customer satisfaction is of primary importance ("We do not want to have just satisfied but enthused customers!"). Ideas are generated on the basis of internet research, journals, trade fairs or suppliers. However, a major source for idea generation lies in the customer needs gathered from personal counselling talks or surveys.

2. Motives for joining a network of SMEs: From the executives' perception, the "WirtschaftsForum Neuwied e.V." offers a regional platform, which enables 
a) external presentation of the companies to communicate core business and services across the SME-network and b) exchange of services, especially requests received from other companies within the SME-network and orders placed with participating partners. The interview partners were primarily interested in gaining economical benefits from cooperation.

3. Prerequisites for effective collaboration: At present, the initial expectations of the interviewees when joining the "WirtschaftsForum Neuwied e.V." are not entirely met. In this regard the network has to address the requirements below:

- General survey of the member structure. Interview partners expressed the wish to obtain relevant, useful information on other member firms on the network's website. So far, information on the member structure of "WirtschaftsForum Neuwied e.V.", i.e. represented industry sectors, business areas and services provided, is not available.

- Cooperativeness- Collaboration requires continuous exchange of information and knowledge. The willingness to cooperate therefore depends on the company's economic benefit for all cooperating partners.

- Integration of the employees' level- Employees have not been involved in network activities so far. At present, the companies of the network are exclusively collaborating on the executives' level. Integration of the operational employees' perspective is therefore required.

4. Benefits of using Web 2.0: Implementation of a Web 2.0-platform is expected to foster effective collaboration within the "WirtschaftsForum Neuwied e.V.". The managers propose a simple Web 2.0-application with network-members represented in a fact sheet. The application is supposed to provide a straightforward search function which allows easy access to the required enterprise information. In addition, regional customers might use this function to find solutions related to an individual problem. The Web 2.0-application is then to be gradually extended by additional functions such as a forum for exchanging experiences, idea generation or idea testing on the market.

5. Success factors of SME 2.0: SME 2.0 is vitally dependent on the participation of its users. The successful implementation of Web 2.0-applications within a network of SMEs requires active employees interacting on the overall platform. User participation itself is a question of trust, balance of effort and benefit as well as technical aspects: The Web 2.0-based platform needs to meet technical requirements such as easy access and use. The goals and benefits of the application have to be obvious for each enterprise and each single user. Security aspects such as preventing users from diffusing wrong or manipulated information that could negatively affect the company have to be addressed with priority. In order to cope with the problems of limited time resources and information overflow on the participants' side, all relevant information has to be rapidly and easily available.

\subsection{SME 2.0 vs. Web 2.0-Based Open Innovation}

As discussed in the previous section, open innovation needs a mental change from closed to open development of ideas based on external resources. Our research is 
focused on idea generation within employees' communities that are exchanging creativity and ideas in a Web 2.0-based environment of cooperating SMEs. This requires active participation of all employees acting independently of their companies' organizational structure. However, according to our results, the participation willingness rests upon conditions such as trust, security of sensitive data, and balance between effort and economical benefit. Given this context it can be assumed that the executives try to influence their employees' activities within SME 2.0 as well as the content that is generated with Web 2.0-applications. As a consequence we recommend an incremental approach towards Web 2.0-based open innovation as well as the direct implementation of first Web 2.0-applications. Since trust has to be built up by cooperation (Gambetta 2000), this approach enables the establishment of a Web 2.0based platform meeting executives' needs but also objections. Thereby clearly described goals and rules of cooperation in SME 2.0 help to significantly reduce concerns towards the use of Web 2.0 (Volery and Mensik 1998).

\section{A Roadmap towards Open Innovation within SME-Networks}

Based on the analyzes of SMEs, their approach towards Web 2.0, and collaborative open innovation presented so far as well as the first interviews led with companies from "WirtschaftsForum Neuwied e.V.", the present section develops a general framework of interaction within networks of SMEs and outlines a roadmap for open innovation in this context. Interpretation of the research outcomes stemming from "WirtschaftsForum Neuwied e.V.", makes up for the first building block of the framework.

\subsection{Interpreting the Case of "WirtschaftsForum Neuwied e.V."}

The companies of the network "WirtschaftsForum Neuwied e.V." pursue the goal of "acting in common". As described beforehand and concretized on their common website, "acting in common" ranges from fostering company relations and cooperation activities among the networking partners to establishing a common (internet) appearance vis-à-vis the outside world.

The companies of the network are already taking an active part in cooperating within a range of areas which are non-critical from a competitive perspective. Basically they are engaging either in the bundling of needs and resources, such as is the case for procurement, or in sharing experience e.g. concerning issues of leadership and personnel. An important cooperation field at present is the set up of common standards for the training systems employed during apprenticeship of young workers. Because of its character, shared resource use is the term applied for this kind of cooperation activities within the network.

Looking at the case of "WirtschaftsForum Neuwied e.V." from this perspective shifts the initial research question into the question of how it is possible to move from a state of shared resource use to a state of open innovation within a network of SMEs. Within this context, the internet and especially Web 2.0 applications are seen as a means of stimulating interaction among the firms of the network. 
On a very general level, the first set of interviews conducted so far suggests that companies of the heterogeneous network "WirtschaftsForum Neuwied e.V." prefer an incremental step-by-step-approach towards closer cooperation, thus slowly intensifying the interaction of the partners involved. Besides, the interviews show a strong need for a better market and thus customer access via the network. In more specific terms, the interviews reflect a demand for cooperating in different areas of activities. These areas of cooperation can be arrayed conforming to the degree of reciprocity they reflect in the following, increasing order:

- Exchanging general information: This activity is directed at promoting the network's partners main willingness to cooperate and at preparing the ground for further cooperation efforts. It is mutually trust-building on the one hand and meets a very practical need of exchanging basic information at an early stage of the cooperation on the other. Providing general information on the business activities of the company and details of contact persons engaged in cooperation activities are a typical example for this area of interaction. Exchanging general, useful information on business matters can be interpreted as a prerequisite for further cooperation within a network and also as a first step towards activating the partners' interaction willingness. As it can be helpful in the day-to-day work, it is furthermore a way of making employees of all hierarchical levels active partners of the cooperation.

- Broadening market access: This is the case where cooperation within the network by means of Web 2.0 is looked at as a way to becoming better known within the network and thus raising the number of demand-driven contacts - and probably business transactions - with potential customers. In more active terms, better knowledge of the networking partners can help firms approach potential customers within the network with attractive pricing models and customer-specific offers. An example could be a fitness and health centre giving special member discounts or holding in-house-courses at its partners' offices addressing the specific needs of their workforce. All cases of broadening market access planned so far have the common factor that firms look at partners of the network and their employees in their capacity as potential customers.

- Establishing sales partnerships: In this case the network is intended to be used in order to establish a partnership of suppliers. Cooperation within the network in this context is meant to create comprehensive business solutions for customers who would otherwise have to contract several suppliers and thereby incur higher transaction costs, saving them the cost of establishing additional business contacts. An example for this kind of cooperation could be the case of several manufacturers and traders of heating, isolating, and security systems providing an overall energy and safety solution to a future homeowner. In contrast to the case of broadening market access this type of cooperation activity is genuinely network-oriented, however frequently with view to a network-external, private customer.

- Generating new ideas by interacting with the customers: Central to this type of cooperation is the explicit interaction between a supplier and her customer for the sake of generating new ideas and business solutions. An example for this case could be a staff training institute developing new training methods and contents in close cooperation with its customers; or a software firm offering its customers the possibility of conjoint product development and testing, thus letting them exert 
influence on the design and functionality of its products and services. Of all the cases discussed so far, this one is the closest to open innovation and is characterized by the highest degree of reciprocity between the cooperating partners. This is true even if the interaction takes place at the boundaries of the network as is the case for network-external customers.

\subsection{Interaction within Networks of SMEs: A General Framework}

Analysis of the first interview results has helped systemize the cooperation activities the members of "WirtschaftsForum Neuwied e.V." are undertaking on the basis of potential areas of interaction the networking companies engages in. As for the areas of interaction, four types of network cooperation could be identified: information exchange, market access, sales, and idea generation. Since the present analysis is based on the outcomes of a few explorative interviews, the enumeration of interaction areas is most likely not to be exhaustive.

The empirical material gathered from the interviews as well as first theoretical considerations on this topic suggest that there might be yet another dimension of interaction important for achieving collaborative open innovation within company networks. This dimension is the general focus of the interaction in question. Looking at the focus of interaction two cases can be distinguished: the case of directly creating interaction value and the case of indirectly creating it.

- Direct creation of interaction value covers all interactions targeted at improving sales as well as resource and cost efficiency. Activities within this field of interaction are directly contributing to a firm's overall profit. The interviews show a strong preference for cooperation efforts along this line of reasoning. Companies of "WirtschaftsForum e.V." explicitly want to engage in "win-win-activities" with regard to short-term profits.

- Indirect creation of interaction value addresses all activities which are not creating direct value and at first sight maybe are not creating a value at all. The important thing about interaction activities which indirectly create value is that viewed from a broader perspective they are not only creating value for the business but can even become critical from a strategic point of view. This is the case for establishing favourable working conditions in order to attract excellent work force. With regard to the demographic developments that the societies of the Western World are facing, attracting highly motivated and skilled workforce is becoming increasingly difficult especially for small and medium-sized companies. Therefore, engaging in activities that improve working conditions and are thus render the working place more attractive might very well contribute to a firm's overall goal of profitable growth. Cooperation activities within this context can be especially promising, since they could make a business location as a whole - in this case the "WirtschaftsForum Neuwied e.V." - more attractive for highly skilled and motivated workforce. A long-term win-win-situation for networking partners can therefore be achieved.

Summing up, the analysis presented so far makes up for the following general framework of interactions within networks of SMEs: 


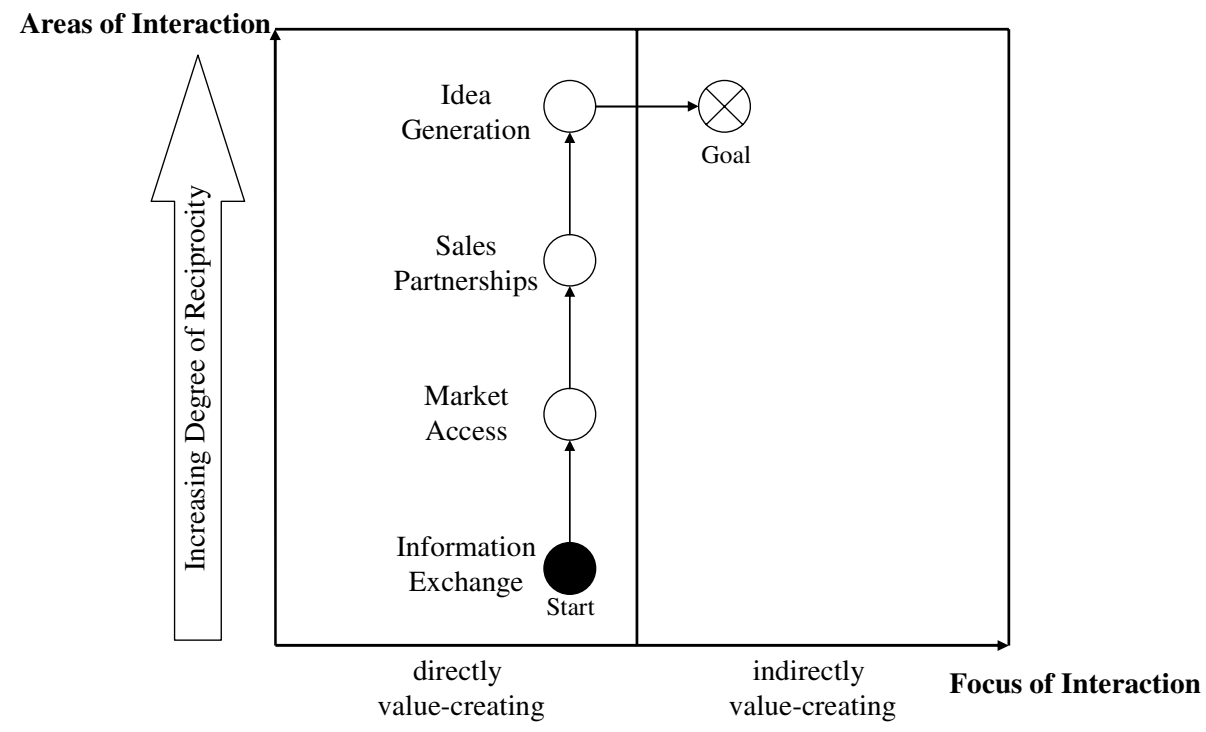

Fig. 2. Framework for Network Interaction

\subsection{A Roadmap towards Web 2.0-Based Open Innovation}

The general framework of interaction within SME-networks developed in the prior section builds the basis for the roadmap proposed towards Web 2.0-based open innovation. The previous sections covering the interview results and the theory of open innovation give essential clues for the concrete design of the approach recommended here. In accordance with the analyses made so far, the following recommendations hold:

- In order to generate short-term, direct value of interaction, firms should engage first in cooperation activities which are directly value-creating.

- As for the directly value-creating cooperation activities, companies should choose those areas of interaction that best fit their business needs. These can e.g. be in the fields of information exchange, market access, sales partnerships, or idea generation.

- A first step to build up trust among the networking partners and to activate their interaction willingness should be the mutual exchange of information.

- An efficient way to exchange information within a Web 2.0-based environment is the creation of a simple market platform.

- Moving towards collaborative open innovation means gradually shifting cooperation efforts towards (a) indirectly value-creating interaction activities and (b) interaction for the sake of common idea generation, be it within the network or at its boundaries.

\section{Outlook}

The properties of small and medium-sized companies on the one hand and the requirements for fruitful Web 2-0 based collaboration in company networks on the 
other hand make Web 2.0-based interaction activities within networks of SMEs a challenging field of research. Because of their inherently conflicting principles of (inter-)action, it is a demanding task to bring these two fields of research - networks of SMEs and Web 2.0 - together. Our paper points at the necessity of changing culture within SMEs in order to overcome the depicted gap: A corporate culture is required which not only accepts the employees of all hierarchical levels taking an active part in the cooperation, but also encourages them to do so.

Another area for future research lies at the heart of the following area of conflict which is distinctive for open innovation: The more partners involved in activities of common idea generation, the higher the probability of generating a truly new idea and business solution. The more partners who are interacting and generating vast amounts of ideas, the more important is the coordinating and channelling of interaction activities and outcomes, either from a security point of view or for content structuring reasons. These two research issues will have to be covered by subsequent research.

\section{References}

Alves, J., Marques, M.J., Saur, I., Marques, P.: Creativity and Innovation through Multidisciplinary and Multisectoral Cooperation. Creativity and Innovation Management 16(1), 27-34 (2007)

Bellmann, K., Gerster, B.: Netzwerkmanagement kleiner und mittlerer Unternehmen: Eine theoretische und empirische Untersuchung. In: Bellman, K., Becker, T. (eds.) Wertschöpfungsnetzwerke, pp. 53-68. Erich Schmidt Verlag, Berlin (2006)

Birkinshaw, J., Bessant, J., Delbridge, R.: Finding, Forming and Performing: Creating Networks for Discontinuous Innovation. California Management Review 43(3), 67-84 (2007)

Burns, P.: Entrepreneurship and Small Business. Palgrave, Hampshire (2001)

Chesbrough, H.: The Logic of Open Innovation: Managing Intellectual Property. California Management Review 45(3), 33-58 (2003)

CoreMedia, Berlecon Research: Enterprise 2.0 in Deutschland - Verbreitung, Chancen und Herausforderungen. A Study on behalf of CoreMedia conducted by Berlecon Research (2007)

Corsten, H.: Grundlagen der Koordination in Unternehmensnetzwerken. In: Corsten, H. (ed.) Unternehmensnetzwerke, Oldenburg, München, pp. 1-57 (2001)

De Saulles, M.: SMEs and the Web - Executive Summary. University of Brighton (2008a)

De Saulles, M.: Never too small to join the party. Information World Review (September 3, 2008b),

http: / /www.iwr.co.uk/information-world-review/features / 2225252 / never-small-join-party (last access: March 12, 2009)

Dewett, T.: Linking intrinsic motivation, risk taking, and employee creativity in an R\&D environment. R\&D Management 37(3), 197-208 (2007)

European Commission 2003: The new SME Definition - User guide and model declaration. Enterprise and Industry Publication (2003)

European Commission: Observatory of European SMEs - SMEs and cooperation. Enterpise Publication 2003/5 (2003a)

Gambetta, D.: Can We Trust? In: Gambetta, D. (ed.) Trust Making and Breaking Cooperative Relations, pp. 213-237. Basil Blackwell, London (2000) 
Human, S.E., Provan, K.G.: External Resource Exchange and Perceptions of Competitiveness within Organizational Networks: An Organizational Learning Perspective. Frontiers of Entrepreneurship (1996)

Kratzer, J., Leenders, R.T., van Engelen, J.M.L.: Stimulating the potential: Creative performance and communication in innovation teams. Creativity and Innovation Management 13(1), 63-71 (2004)

Lakhani, K.R.: Innocentive.com. Harvard Business School case No. 9-608-170 (2008)

Levy, M., Powell, P.: Strategies for Growth in SMEs - The Role of Information and Information Systems. Information Systems Series (ISS). Elsevier, Oxford (2005)

Martins, E.C., Terblanche, F.: Building Organizational Culture that Stimulates Creativity and Innovation. European Journal of Innovation Management 6(1), 64-74 (2003)

McAfee, A.P.: Enterprise 2.0: The Drawn of Emergent Collaboration. Sloan Management Review 47(3), 21-28 (2006)

McKinsey and Company: Building the Web 2.0 Enterprise: Mc Kinsey Global Survey Results. The McKinsey Quarterly (July 2008)

Milles, M.B., Huberman, A.M.: Qualitative Data Analysis, 2nd edn. Sage Publications, Thousand Oaks (1994)

Oldham, G.R., Cummings, A.: Employee creativity: Personal and Contextual Factors at Work. The Academy of Management Journal 39(3), 607-634 (1996)

O'Reilly, T.: What Is Web 2.0 - Design Patterns and Business Models for the Next Generation of Software (2005),

http://www. oreillynet.com/pub/a/oreilly/tim/news/2005/09/30/ what-is-web-20.html (last access: March 12, 2009)

Osterloh, M., Rota, S.: Open Source development - Just another case of collective invention? Research Policy 36, 157-171 (2007)

Picot, A., Reichwald, R., Wigand, R.T.: Die grenzenlose Unternehmung - Information, Organisation und Management. Gabler, Wiesbaden (2003)

Piller, F.T., Walcher, D.: Toolkits for idea competitions: a novel method to integrate users in new product development. R\&D Management 36(3), 307-318 (2006)

Romme, A.G.L.: Making a Difference: Organization as Design. Organization Science 14(5), 558-573 (2003)

Schaarschmidt, M., Von Kortzfleisch, H.: Social networking platforms as creativity fostering systems: Research model and exploratory study. University Koblenz-Landau, Computer Science Department Working Paper Series No. 9/2008 (2008)

Social Computing News Desk (2008): Web 2.0 is All About Using the Power of the Web Business Advantages, Says Expert. Social Computing Magazine (May 25, 2007) (2008) (last access: March 12, 2009),

http: / /www. socialcomputingmagazine.com/

viewcolumn. cfm?colid=249\#bio

Street, C.T., Cameron, A.F.: External Relationships and the Small Business: A Review of Small Business Alliance and Network Research. Journal of Small Business Management 45(2), 239-266 (2007)

The Economist Intelligence Unit: Serious Business - Web 2.0 Goes Corporate. Report from the Economist Intelligence Unit Sponsored by FAST (2007)

Thielemann, F.: Die Gestaltung von Kooperationen kleiner und mittlerer Unternehmen. Innovation: Forschung und Management. No.7, IAI Institut für angewandte Innovationsforschung, Bochum (1996)

Tierney, P., Farmer, S.M., Graen, G.B.: An examination of leadership and employee creativity: the relevance of traits and relationships. Personnel Psychology 52, 591-620 (1999) 
Van der Meer, H.: Open Innovation - The Dutch treat: Challenges in thinking in business models. Creativity and Innovation Management 16(2), 192-202 (2007)

Volery, T., Mensik, S.: The Role of Trust in Creating Effective Alliances: A Managerial Perspective. Journal of Business Ethics 17, 987-994 (1998)

Von Hippel, E.: Sticky Information and the Locus of Problem Solving. Management Science 40, 429-439 (1994)

Von Hippel, E.: Democratizing Innovation. MIT Press, Cambridge (2005)

Von Kortzfleisch, H., Mergel, I., Manouchehri, S., Schaarschmidt, M.: Corporate Web 2.0 Applications: Motives, Organizational Embeddedness, and Creativity. In: Hass, B., Walsh, G., Kilian, T. (eds.) Web 2.0: Neue Perspektiven für Marketing und Handel [trans. New Perspectives in Marketing and Business], pp. 73-89. Springer, Berlin (2008)

West, J., Lakhani, K.: Getting Clear About Communities in Open Innovation. Industry and Innovation 15(2), 223-231 (2008) 